\title{
Alliance in Common Factor Land: A view through the research lens ${ }^{*}$
}

\author{
Adam O. Horvath 1
}

\begin{abstract}
The alliance has evolved into one of the most researched psychotherapy process variables. In this paper it is argued that migration of the concept of the alliance from its psychodynamic roots onto "Common Factor Land" has brought not only great benefits but substantial challenges as well. Currently the alliance has no consensual definition, nor has its relation to other relationship constructs been clearly charted. As a consequence, alliance assessment tools have been substituted for a concept definition and taken over the grounds that theorizing about a construct would normally occupy. The historical background of the events that lead to the current state are reviewed and some consequences of positioning the alliance on the conceptual space where Common Factors "live" are examined. Some possible avenues of moving the alliance project forward and re-connecting the empirical research to clinical practice are explored.
\end{abstract}

${ }^{1}$ Simon Fraser University, Burnaby, BC, Canada

Correspondence: prof.AOH@gmail.com

The preparation of this paper was supported, in part, by Grants of Social Sciences and Humanities Research Council (Canada)

\footnotetext{
* Portions of this paper were presented at the annual conference of the American Psychological Association (2009, August) Toronto, Canada.
} 
Measured by the common-sense metric of the number of research papers published on the topic, the alliance has to be judged as a prodigious success. Entering the key-word "alliance" into the PsychInfo database brings up a list of over 6000 articles which have been published over the last 20 years. Clearly, the notion of the alliance has captured the attention and imagination of researchers like few other topics in the history of psychotherapy research. Looking beyond the number of publications, however, there appears to be a growing unease among some of the leading researchers in the area of therapy relationship about the theoretical ambiguities that seem to persist concerning the alliance [2006 \#1102]. And yet, it is likely that this lack of clarity and consensually accepted definition of the modern version of the alliance is also responsible for the concept's popularity across such a broad spectrum of investigators and in such diverse contexts.

In the first part of this paper I will attempt to summarize what I believe to be the historical roots behind both the popularity and ambiguities surrounding this concept. In the second part of the article I will indicate some possible avenues of progress I see as viable avenues we could use to move forword towards developing the research on the alliance in useful directions both theoretically and pragmatically.

\section{A brief look at the "rear view mirror"}

To understand the current challenges facing those of us who do research on the alliance, and to make a case for my claim that there are serious challenges facing us, I will briefly review the history of the development of the notion of an alliance between a therapist and client.

The concept of alliance has deep roots in psychodynamic theory. Freud (1912/1958) noted the paradoxical situation the client finds him/her self in at the beginning of treatment: the analytic process activates the client's defenses and yet she or he must overcome this obstacle, and rise above the negative responses to transference in order 
to stay in analysis and actively engage in the therapeutic work. Prior to introducing the topic, Freud concerned himself almost exclusively with the negative transferential aspects of the analyst-analysand relationship. In 1912 volume "The dynamics of transference" he serves notice that the model of the relational dynamics between therapist and client must be extended to accommodate the client's positive engagement and active collaboration in the therapeutic work in spite of the challenges and pain of reprocessing hitherto repressed memories. Meissner summarizes his dilemma succinctly:

"He recognized that factors allowing the patient to persist in the analytic effort in the face of these powerful resistances were somehow connected to the relationship to the analyst, but he had nowhere to put these motives except in transference. As a result, positive transference became for him the aspect that enabled the patient to see the analyst as an authority to be trusted and believed"

(Meissner, 2001b, p. 222).

In elaborating his idea of the patient's positive collaborative stance, Freud suggested that the client "clothes" the therapist with the qualities of individuals with whom/she has had positive relations. But, of course, the metaphor of the client covering the therapist with such positive memories is a "shorthand" which leaves a lot of questions unanswered: Where does the analysand's motivation and resources come from? Is this a conscious, ego driven process, or is the "unobjectionable transference" driven by unconscious motives and subject to the same distortions as transference? What contributions can, or should, the therapist make to strengthen the process? Freud never fully attended to these problems, and the issue of the client's positive, perhaps conscious, attachment to the therapist and the therapy process, remained problematic ${ }^{1}$ among many analytical theorists.

\footnotetext{
${ }^{1}$ For a good discussion of the topic see: Meissner 2001a and 2001b.
} 
In the 1950s Zetzel (1956) and Greenson (1965) re-explored the notion of the client's "positive alignment," coined the word "alliance," and attempted to resume work on Freud's "unfinished project." They used the concept of the observing/conflict free ego to locate the client's resources which enable the patient to "objectively" reflect on the therapy process and make disinclinations between their transference based projections and the "real" therapist ${ }^{2}$.

However, the reaction to the effort to assert the alliance as the third (along with transference and the real relationship) active component of the therapist-client relationship remained (and remains) controversial. The main objection came from a number of important contributors who believe that all aspects of the relation between therapist and client are transference based, and proposing a relational dynamics outside this framework was confusing at best, and dangerous at worst (e.g., Brenner, 1980). Their core argument was that a notions such as "observing ego" or indeed any suggestion that conscious, non transference based, elements of the relationship play a significant role in analysis would distract the therapist's attention from the focus of the work which is the interpretation of transference. Transference, in some form, in this perspective encompass the whole therapist-client relationship. This is where things stood until both Luborsky (1976) and Bordin $(1975,1976)$ each put forward proposals that the concept of the alliance could be lifted clean out of its psychodynamic theoretical framework, and introduced the idea that the alliance may be a common and ubiquitous component of all helping relationships.

It is important to consider the historical/intellectual context in which this idea of the alliance as generic therapy ingredient was put foreword. It happened at a time when the research community was trying to come to terms with the "Dodo Bird Verdict," a finding primarily

2 Other analytical writers such as Ferenczi and Sullivan indicated lively interest in the issue and took a very different approach to therapist-client relationship to avoid this dilemma. 
based on Smith \& Glass' (1977) meta-analysis, suggesting that different "brands" of psychological treatments, based on different theoretical models, produced nearly identical benefits for the clients. The most prevalent interpretation of the "Verdict" was that there were some underlying common factors operative across different treatments, and these common ingredients were responsible for the lion's share of what makes therapy "work."3 As a consequence, there was a great deal of interest in locating variables that could account for these "common ingredients."

It was in this context that Bordin and Luborsky moved the concept of the alliance to the "pan-theoretical" stage by "divorcing" the theory of the alliance from its psychodynamic roots and by dissociating the idea of the alliance from specific modes of therapy. These moves gave rise to a concept rather unique in the psychotherapy literature; one which largely relied on "commonsense" lexical understanding for its definition as opposed to most of the variables we use in psychology which are subject to "persuasive definition," a form of defining which takes the concept beyond its "customary" form (as it is usually understood in non-professional conversation) by stipulating specific use and specific delimiters of its extent unique to the way the concept is applied within the cognate area.

It is also useful to note at this juncture that our understanding of the "pan-theoretical alliance" is essentially based on only two theoretical sources: Bordin's seminal contribution was introduced in his SPR presidential address (1975) which was subsequently published in a slightly edited form in (1976). Luborsky discussed his perspective on the topic in a chapter of the book "Successful psychotherapy" in 1976. Although both of these authors (especially the former) are often referred to as having defined the "modern" concept of the alliance, I believe that

\footnotetext{
3 There were earlier proponents of the "common factor" theory (see Rosenzweig, 1936; Frank and Frank, 1991) as well as those who did not agree with this interpretation of the "Dodo Birds' pronouncements (e.g., Chambless, 2002).
} 
these claims are based on two fundamental misunderstandings of these contributions: First, Bordin's and Luborsky's description of the alliance differ in significant aspects. Second, both of these authors' writings are somewhat ambiguous descriptions of the alliance as a process (i.e., how does it come about, what are its purported functions) rather than definitions of a concept (Horvath, 2009a, 2009b).

\section{The search for common factors}

Spurred on by the "Dodo Bird Verdict," many of us had been working to find ways of integrating different psychotherapy models. One of the practical avenues that the psychotherapy integration movement has been pursuing works on the assumption that these common underlying change principles are already built into the various psychotherapy models, but are hidden from sight due to a kind of "Tower of Babel" (TB) effect; different therapies are talking about similar or identical principles using different language/words.

"Psychological Commons" is the label I use to identify the conceptual space we have created to accommodate these pan-theoretical or generic concepts. By fiat of reforming language, an attempt is made to reverse the TB process. Existing constructs such as transference and alliance are brought to the Commons, divested of their theory specific roots and links, and offered up for use by clinicians and researchers of "all stripes," in a kind of pared down, common sense version of the original concept. What we hoped to achieve is a focus on the core change processes without getting tangled up in the minutiae of theoretical links and hinges that cling to the concept in their "home turf." What is sacrificed at the altar of unification is precision as well as the loss of the complex set of the delimiters and qualifiers that made possible for the concept within its "home theory" to be linked as a piece in a coherent whole. At the Psychological Commons, using this process, transference can be pared down to something like "ghosts of the relationship past," 
and the notion of alliance can stand for a host of different aspects of the relationship and, indeed, sometimes for the relationship as a whole.

I do not mean to underestimate the value of searching for common language; the weeding away of some of the overblown theoretical complexities, and digging for the core transformational processes in therapy. It stands to reason, and I firmly believe it is true, that there has to be a finite number of processes that are activated in successful therapy. It is equally likely that there are no unique, non overlapping sets of change processes that are exclusive to each different kind of therapy. It seems, however, worthwhile to examine the trade-offs involved in bringing constructs developed within a theoretical model into the "Psychological Common" using a liberal or permissive languagebased approach, and hoping that the construct will find its proper home among the different theoretical models that continued to exist and to which most of us seem to commit our allegiance to ${ }^{4}$.

Loosening the boundaries of a construct makes it easy to adopt and use it without challenging the fundamental assumptions underlying the differences between theories of psychotherapy. However, there is also a risk that, using this process, the construct simply becomes a synonym for something that already exist (by a different name perhaps) in the "host's" theory, and creates a Tower of Babel problem in reverse: The discourses, originating within different theoretical circles, now use the same words, but to mean different things.

\section{Will the "real" alliance please stand up?}

It appears to me very likely that we are facing such challenges in the current evolution of research on the alliance. The alliance concept,

\footnotetext{
${ }^{4}$ I am well aware that, in recent surveys, close to the majority of clinicians seem to profess an "eclectic" stand. It seems to me that these statistics reflect on the fact that many of us are "eclectic" in the technical sense; we are prepared to borrow tools from a variety of sources. But insofar as theoretical models provide a more or less coherent organizing structure to orient ourselves when contemplating the nature of human development, aetiology of psychological problems/illness, and the sources of healing and change, I would argue that very few are "a-theoretical" in this important sense.
} 
removed from its psychodynamic theoretical roots, migrated to the Psychological Commons, and at once became more popular and more diffuse. It is important to note that the alliance construct has generated very little theoretical discourse since Bordin and Luborsky moved the idea on to the "Commons." Instead, various groups developed measures that empirically and practically implemented a variety of conceptualizations of the alliance. This is to say, instead of a rigorous theoretical debate within the cognate community that was to use the concept - which would have yielded not only a definition of what the alliance is, but perhaps even more importantly, what it is not, and how it fits with other existing relationship constructs - we skipped right past the conceptual purgatory and went straight to "empirical bliss." Or so it seemed.

As of last year, over 65 different methods of assessing the alliance have been documented (Elvins \& Green, 2008). It is, of course, not unusual for a psychological construct to be assessed through a variety of means; there are different points of references (client, therapy is, observers), different contexts, and different age groups to consider. However, a plurality of over 60 assessment methods in English alone, should call our attention to the fact that something out of the ordinary might be happening. I believe that these many methods of assessment represents the current state of 'de facto' plurality of definitions of the alliance construct. Thus these alliances are pan-theoretical - in the plural, but unique to each assessment - in singular. This does not mean that these diverse assessment methods measure entirely different underlying constructs. There is good reason to believe that the most popular measuring instruments share, to a differing degree, a common focus on collaboration (Hatcher, Barends, Hansell, \& Gutfreund, 1995). However, even these "core instruments,"5 include much else beside the

5 The "core instruments" include the VPPS, CALPAS, HAQ and the WAI, These assessment tools are "core" in the sense of popularity of use as reported in the literature (Horvath \& Bedi, 2002). 
common collaborative element. In an earlier study (Horvath, 2009c) we found that less than $50 \%$ of the variance was shared among these most commonly used measures. Additionally, there is very little data available on the discriminant validity of the available tests; we have less than adequate evidence that the measures most of us have been using to measure alliance are measuring only "the alliance" and not something else in the relationship. The situation, of course, is even worse when researchers make inferences about the alliance on the basis of process measures developed for other concepts (e.g., empathy) or use subsets of alliance measures and assume that the variance captured is attributable to the alliance (Horvath 2009a, 2009b).

\section{The impact of the "status quo"}

How serious is the impact of the ambiguity and mis-measurement of the alliance concept? Let us look at the alliance rupture research literature as an example: Bordin (1994) suggested that that the management of stresses in the alliance makes an important contribution to the therapy process. A significant body of research literature has built up in examining these "rupture-repair" cycles. Within this literature one can find some exceptionally useful finegrained analysis of psychotherapy process. However, this significant body of work is also deeply fragmented. Some researchers use methods of detecting ruptures by analyzing therapy discourse at a single utterances or thought units level. Others use the sequence of events that may range from a single therapist-client exchange to a series of dialogical sequences within a session. Yet other researchers define ruptures as fluctuations between sessions or even phases of therapy (Lingiardi \& Colli, 2009; Safran, Muran, Samstag, \& Stevens, 2001; Stiles, Glick, Osatuke, Hardy, Shapiro, Agnes-Davies, et al., 2004). In each case the method of assessment "stands in" or assumes the role of defining alliance rupture and, in effect, brackets the important results 
of the researcher's investigation within the constrains of this implied definition. Observations and conclusions about alliance ruptures made within each of these enclosures are not easily linked or extrapolated from one to another. Each type of investigation, each approach to measuring the alliance rupture, makes an important and significant contribution, but the insights uncovered by each project are marooned in a method-determined "definition island." As a consequence, knowledge gained about "alliance ruptures" does not aggregate easily, nor do the findings become more robust through independent corroboration.

Also, within this research literature, the kind of data that is interpreted as evidence that a rupture has taken place varies significantly with the researcher's method of assessment. At one end, almost any sign of momentary tension between therapist and client is assumed to signal some kind of rapture (Safran \& Muran, 2000, 2006). Near the other end of the continuum, significant fluctuation in self reported alliance between sessions are the criteria that trigger the presence of a rupture (Stiles et al., 2004). It is difficult to know, and yet to be documented, whether these micro-tension ruptures lead to the session level disruptions. Both kinds of investigations identify processes that have potential practical and theoretical importance. But currently they only share the same label "alliance rupture" and leave clinicians adrift in trying to appreciate what alliance rupture is about.

I used a particular line of research - rupture repair cycles - to illustrate the consequences of fragmentation, but I would argue that to a lesser or greater extent the instrument based poly-definition of the alliance has similar effect on most if not all branches of alliance research at the present.

\section{Conclusions}

Making the concept of alliance available to clinicians and researchers 
across the spectrum of therapeutic orientation has achieved a great deal: It has brought into focus the importance of the relationship in general, and the value of a collaborative, responsive stance on the therapist part in particular. It has provided strong empirical support to Frank's insight that therapy is a "dance," a joint accomplishment arising from a special kind of engagement between therapist and client (Frank \& Frank, 1991). This, in itself, has been a remarkable achievement coming as it did in the historical time when ever greater emphasis was being laid on method and technique. Research on the alliance has also provided strong support for moving away from the "medical model" and contextualizing therapy within a broader epistemological framework (Wampold, 2001).

Research on the alliance has also contributed to our knowledge about the importance and fragility of the first few sessions of treatment. We now know with greater certainty than ever before that if clients and therapist do not agree on certain key elements of treatment, feel in accord about what is needed to accomplish, and have a solid personal relationship and respect for one another, therapy may fail.

The aim and justification of studying therapy is to gain insights which will help us provide more effective and efficacious help to our clients. These are the same goals we must keep in sight in charting the course for future directions in alliance research. In order to keep bridging the world of researchers and that of therapists, we need to move beyond documenting the relation with the outcome, and to discover and document more clearly the kind of interactive processes that most likely foster the alliance. Likewise, we need to focus on studies designed to better understand both the direct and indirect affects off maintaining or repairing the alliance, and to better understand how the alliance functions in the mid-and late phases of therapy. In order to accomplish these goals we need to overcome some 
of the fragmentations in our collective efforts and reduce the "fuzziness" around the alliance concept I have described earlier.

\section{How can we reach these goals?}

It appears quite unlikely that a consensually excepted, universal, definition of the alliance is likely to emerge anytime soon. It seems equally unlikely that the research community will voluntarily give up many of the 60+ assessment methods to bring the alliance research literature into greater harmony. Therefore a practical first step to move us towards a more coherent research agenda, I believe, begins with the recognition of both the similarities and the differences among the constructs currently labeled alliance. Such "reclassification" need not to lead toward a diminishment of the importance of the construct, nor does it necessarily limit its universality, but it would help us to identify what is a common core amongst our different ways of understanding the alliance and at the same time permit the specification of components unique to certain perspectives/measures.

The second important step, which I believe is within practical reach, is a clearer classification of the relationship constructs currently in use. We need to develop a model of the relationship components that would facilitate the linking of the many relation constructs that are used in the research and clinical literature. There is strong evidence that many of these constructs make significant contributions to the therapy process (e.g., Norcross, 2002), but we lack a coherent schema that would help us appreciate how these concepts overlap, augment, or relate to one another. In a previous paper I have suggested that classifying relational constructs along a 3 layered hierarchy (feelings, relational inferences, and relational processes) would be a positive step in this direction (Horvath, 2009c).

My third suggestion is that the research community engage in a discourse directed toward clearing up the persistent "homogeneity 
myth" that suggests that the alliance is realized via the same accomplishments throughout the course of therapy. Reaching consensus with respect to the tasks and goals of treatment seems much more relevant in the opening phases of treatment than in the mature or final phase of treatment. I would predict that the re-consideration of what informs the strength of the alliance in different points of treatment would likely facilitate the identification of the kinds of processes and accomplishments that contribute to alliance enhancing process.

Last, I recommend that we moderate our perspective in our search for the "common" or universal/pan theoretical therapy ingredient. As noted before, both logic and clinical wisdom support the idea that some core change processes are shared by all helping relations. However, these core ingredients manifest themselves only in the particular context of different therapies. As Bordin already noted in 1976, different therapies will have different alliances. It seems that we have paid most attention to what we assume to be the very broadly general aspects of the alliance at the expense of explicit notice and research on the different manifestations of the alliance in diverse kinds of treatments and at different stages of work. Universally common factors "live" at high level of abstraction (as opposed to particular manifestations). As therapy process constructs they are conceptually more akin to "change principles" than to concrete independent variables. Clear acknowledgement of both the "universality" and "manifest specificity" of alliance would likely help us more clearly define what it is and help to generate a research agenda that focuses on "alliance-in-context" that might better bridge the research/practice divide.

\section{References}

Bordin, E.S. (1975, September). The working alliance: Basis for a general theory of psychotherapy. Paper presented at the Society for Psychotherapy Research, Washington, DC. 
Bordin, E.S. (1976). The generalizability of the psychoanalytic concept of the working alliance. Psychotherapy: Theory, Research, Practice and Training, 16, 252-260.

Bordin, E.S. (1994). Theory and research on the therapeutic working alliance: New directions. In A.O. Horvath \& L.S. Greenberg (Eds.), The Working alliance: Theory, research, and practice. New York: Wiley.

Brenner, C. (1980). Working alliance, therapeutic alliance and transference. In H.P. Bloom (Ed.), Psychoanalytic explorations of technique: Discourse on the theory of therapy (pp. 137-157). New York: International University Press.

Chambless, D.L. (2002). Beware the dodo bird: The dangers of overgeneralization. Clinical Psychology: Science and Practice, 9(1), 13-16.

Elvins, R., \& Green, J. (2008). The conceptualization and measurement of therapeutic alliance: An empirical review. Clinical Psychology Review, 28(7), 1167-1187.

Frank, J.D., \& Frank, J.B. (1991). Persuasion and healing: A comparative study of psychotherapy ( $3^{\text {rd }}$ ed.). Baltimore, MD, US: Johns Hopkins University Press.

Freud, S. (1912/1958). The dynamics of transference (J. Starchey, Trans.). In J. Starchey (Ed.), The standard edition of the complete psychological works of Sigmund Freud (Vol. 12, pp. 99-108). London: Hogarth Press.

Greenson, R.R. (1965). The working alliance and the transference neuroses. Psychoanalytic Quarterly, 34, 155-181.

Hatcher, R.L., Barends, A., Hansell, J., \& Gutfreund, M.J. (1995). Patient's and therapist's shared and unique views of the therapeutic alliance: An investigation using confirmatory factor analysis in a nested design. Journal of Clinical and Consulting Psychology, 63, 636-643.

Horvath, A.O. (2009a). Conceptual and methodological challenges in alliance research: Is it time for a change. Paper presented at the European Regional Meeting of the Society for Psychotherapy Research, Bozen, Italy.

Horvath, A.O. (2009b). The relationship in therapy. Paper presented at the Society for Psychotherapy Research.

Horvath, A.O. (2009c). How real is the "Real Relationship"? Psychotherapy Research, 19(3), 273-277.

Horvath, A.O., \& Bedi, R.P. (2002). The alliance. In J.C. Norcross (Ed.), Psychotherapy relationships that work: Therapist contributions responsiveness to patients (pp. 37-70). New York: Oxford University Press.

Horvath, A.O., \& Luborsky, L. (1993). The role of the therapeutic alliance in psychotherapy. Journal of Consulting and Clinical Psychology, 61, 561-573.

Lingiardi, V., \& Colli, A. (2009). The Collaborative Interactions Scale: A new transcript-based method for the assessment of therapeutic alliance ruptures and resolutions in psychotherapy. Paper presented at the European Regional Conference of the Society For Psychotherapy Research.

Luborsky, L. (1976). Helping alliances in psychotherapy. In J.L. Cleghhorn (Ed.), Successful psychotherapy (pp. 92-116). New York: Brunner/Mazel.

Meissner, W.W. (2001a). A note on transference and alliance: I. Transference: Variations on a theme. Bulletin of the Menninger Clinic, 65(2), 194-218.

Meissner, W.W. (2001b). A note on transference and alliance: II. Patterns of interaction. Bulletin of the Menninger Clinic, 65(2), 219-245.

Norcross, J.C. (Ed.). (2002). Psychotherapy relationships that work: Therapist contributions and responsiveness to patients (First ed.). New York: Oxford 
University Press.

Rosenzweig, S. (1936). Some implicit common factors in diverse methods of psychotherapy. American Journal of Orthopsychiatry, 6, 412-415.

Safran, J.D., \& Muran, J.C. (2000). Negotiating the therapeutic alliance: A relational treatment guide. New York: Guilford Press

Safran, J.D., Muran, J.C., Samstag, L.W., \& Stevens, C. (2001). Repairing alliance ruptures. Psychotherapy: Theory, Research, Practice, Training, 38(4), 406-412.

Safran, J.D., \& Muran, J.C. (2006). Has the concept of the therapeutic alliance outlived its usefulness? Psychotherapy: Theory, Research, Practice, Training, 43(3), 286-291.

Smith, M.L., \& Glass, G.V. (1977). Meta-analysis of psychotherapy outcome studies. American Psychologist, 32, 752-760.

Stiles, W.B., Glick, M.J., Osatuke, K., Hardy, G.E., Shapiro, D.A., AgnewDavies, R., et al. (2004). Patterns of Alliance Development and the RuptureRepair Hypothesis: Are Productive Relationships U-Shaped or V-Shaped? Journal of Counseling Psychology, 51(1), 81-92.

Wampold, B.E. (2001). The Great Psychotherapy Debate. Mahwah NJ: Erlbaum.

Zetzel, E.R. (1956). Current concepts of transference. International Journal of Psychoanalysis, 37, 369-376. 